\title{
THEORETICAL FRAMEWORK OF RESEARCH ON FUNCTIONAL FIXATION IN ACCOUNTING
}

\author{
Dominika Korzeniowska*๑ http://orcid.org/0000-0001-5806-933
}

\begin{abstract}
Background. Functional fixation has been originally discovered by psychologists and it consists in the difficulty of noticing the possibility of using an object with a known, specific function in a new, unconventional way. It has been studied by behavioural accounting researchers since 1960s who, with time, adopted the idea into accounting and developed a phenomenon called accounting fixation or data fixation. Despite various experiments conducted in the field, the theoretical framework constituting a basis for such research has not yet been summarized in the literature.
\end{abstract}

Research aims. The paper aims to present theories, models, hypothesis etc. harnessed by researchers to investigate functional fixation phenomenon in accounting.

Methodology. The method of literature analysis available in the Internet was used. The scientific publications' databases were searched by means of the combinations of relevant keywords. Finally, 39 articles and 6 monograph published in the years 1966-2018 were included in the analysis.

Key findings. Studies on functional fixation based on three groups of psychological theories: behavioural decision theory, learning theory and motivation theory. The first two were intended mainly to explain the genesis of this mechanism whereas the last was exploited in research on how to reduce the occurrence of functional fixation in accounting. However motivation theory has not been treated so far as a main theory for the accounting fixation research, but its potential for further studies of this type seems quite promising.

Keywords: functional fixation, behavioural accounting, Brunswik's lens model, prospect theory, anchoring, intrinsic motivation.

JEL Codes: D91, M41

* Faculty of Management, Department of Finance and Accounting University of Social Sciences in Lodz, Sienkiewicza 9, Łódź 90-113, Poland. E-mail: dkorzeniowska@spoleczna.pl 


\section{INTRODUCTION}

The phenomenon of functional fixation was originally discovered by psychologists. The first to describe it was German Gestalt psychologist Karl Duncker (1946). In the 1940s he studied the influence of past experiences on limitations in solving current problems. He proved that the earlier use of an object (box, claws, weights, paperclips) in a specific (typical) way, would have an inhibitory effect on the discovery of a proper, new way of using it. Hence, functional fixation means the lack of skills to use a given object in a non-standard way, different from its original purpose. It negatively affects the ability to solve problems or cope with new situations and it limits creativity.

Why were accounting researchers interested in functional fixation? The scientists "suspected" that this phenomenon may occur in many accounting-related areas and may significantly affect decisions made on the basis of information provided by the accounting system, what was confirmed by the research. The importance of this mechanism is also evidenced by the fact that researchers were inspired by this psychological concept at a relatively early stage of behavioural accounting history within the research area called HIP (human information processing) (more in: Korzeniowska, 2018a). What's more, they developed the idea in their own subdiscipline describing the phenomenon called data fixation or accounting fixation, which, despite many similarities, is slightly different from its genuine "psychological" form. Ijiri et al. (1966), were the first to adopt the idea into accounting. They noticed that people tend to give a specific meaning to objects, which means they are not able to see other meanings or uses of these objects in a new situation. Based on the past experience, human being intuitively associates an object with its value and ignores the fact that the value of the object may at the moment be significantly different from its value in the past. To engraft these observations into accounting, the researchers said that if the results/values of certain accounting categories such as profits or costs are named so, regardless of how they were created (which calculation method was used), even accounting specialists tend to disregard the fact that they could have been calculated based on different valuation methods (e.g. FIFO - LIFO, full cost vs. variable cost etc.). Simply put, data fixation is "an ability on the part of users 
to look behind labels attached to accounting numbers, even in cases where the methods used in the calculations of those numbers are fully disclosed" (Bloom et al., 1984, p. 2). Thus, the problem is the ability to change the decision rule while the accounting results are obtained using different methods (Briers et al., 1997).

In Polish behavioural accounting literature, the subject of functional fixation has not been widely discussed either on theoretical or empirical grounds. Mostly, these were only references of the existence of such a phenomenon (Artienwicz, 2011; Gmińska, 2014; Mazurowska, 2014). Korzeniowska's work (2018b) is the only exception. It outlines the essence of functional fixation in accounting and proposes a typology of research areas devoted to this topic. Such issues are present primarily in English-language literature, mainly articles, describing the results of the experiments. Their authors refer to specific concepts, theories, models, etc. (Dearman \& Schields, 2005) to embed their research into a certain theoretical framework. A more comprehensive approach can be found in the chapters of monographs on behavioural accounting, e.g. Belkaoui, 1989. However, there is no study that would constitute a résumé of theories or concepts used by behavioural accountants in constructing their research on this phenomenon in various accounting contexts.

The paper therefore aims to present theories, hypotheses or models used in the research studies on functional fixation in accounting. Such a review may assist researchers interested in this subject, in constructing their own research and embed them in the appropriate conceptual framework. It may be particularly helpful for Polish accounting scientists who have not thoroughly explored this topic so far.

\section{METHOD}

For the purpose of identifying the theories, models, etc. that became the basis for research on functional fixation in accounting, the analysis of literature available in the Internet had been performed. Electronic databases of scientific publications were investigated. By means of EBSCO multi-search engine the following databases were searched: Business Source Complete, Academic Search Complete, Science Direct, SpringerLink. In addition, the BazEkon database was searched. A Google search engine was also used. 
The search was conducted on the basis of key words (mainly in English) reflecting the subject of this study. The combinations of the following words and expressions were used: behavioural accounting, behavioural aspects, accounting change(s), information change(s), functional fixation, data fixation, accounting fixation, fixity, fixedness, information processing and their equivalents in Polish. Additional search criteria were applied: only records published in Polish or English as reviewed publications were included. 318 results were obtained in English (EBSCO) and 41 (BazEkon) in Polish. It turned out that EBSCO also returned items of medical nature. They were not further analysed. The search base was thus limited to 198 items. Next, the titles and abstracts of the selected publications were examined to verify the relevance of their content. Articles written in Polish only mentioned functional fixation. Therefore, the focus was on English-language literature. Finally, the analysis based on 39 articles and 6 monographs published in the years 1966-2018.

\section{THEORIES, CONCEPTS, HYPOTHESES AND MODELS CONSTITUTING THE FRAMEWORK OF FUNCTIONAL FIXATION RESEARCH IN ACCOUNTING}

Since functional fixation is a phenomenon identified by psychologists, it seems quite obvious that the framework for such research in accounting based mostly on psychological theories. In the literature there are many theories and concepts that "fit" in some way to the topic e.g. bounded rationality (Simon, 1955) or the concept of two systems by Tversky and Kahneman (Kahneman, 2012). However, they are in a sense overarching or more general concepts, applicable to a number of empirical issues present in research conducted within the behavioural trend in economic sciences. Thus, these theories or concepts will not be further discussed herein. The presentation will be limited to those theories, models, etc. that were specific to functional fixation research in accounting. The table 1 outlines a proposal of their systematization. 
Table 1. Theories, models, hypothesis and cognitive mechanisms used in functional fixation research in accounting

\begin{tabular}{|l|l|l|l|}
\hline \multirow{2}{*}{$\begin{array}{l}\text { Behavioral decision } \\
\text { theory }\end{array}$} & $\begin{array}{l}\text { probabilistic } \\
\text { functionalism }\end{array}$ & $\begin{array}{l}\text { Brunswik lens } \\
\text { model }\end{array}$ & \\
\cline { 2 - 4 } & $\begin{array}{l}\text { probabilistic } \\
\text { judgement }\end{array}$ & prospect theory & framing \\
\cline { 2 - 4 } & heuristics & anchoring \\
\hline Learning theory & $\begin{array}{l}\text { stimulus-response } \\
\text { theory }\end{array}$ & $\begin{array}{l}\text { conditioning } \\
\text { hypothesis }\end{array}$ & \\
\cline { 2 - 4 } & interference theory & memory theory & $\begin{array}{l}\text { primacy/recency } \\
\text { effect }\end{array}$ \\
\hline Motivation theory & $\begin{array}{l}\text { self-determination } \\
\text { theory }\end{array}$ & & \\
\hline
\end{tabular}

Source: own study.

\section{BEHAVIOURAL DECISION THEORY}

Behavioural decision theory consists of two major theoretical perspectives that have been used by accounting fixation researchers: probabilistic judgment and probabilistic functionalism.

Brunswik's lens model stems from probabilistic functionalism. It aims to comprehend and describe human behaviour in man's natural environment. It is based on Egon Brunswik's theory of visual perception (Hammond \& Stewart, 2001). It describes how a three-dimensional object in the environment (distal stimulus) transforms into a two-dimensional object in the retina (proximal stimulus). Due to the fact that such a transformation is neither "one-to-one" nor continuous, the mapping between the distal and proximal stimuli is probabilistic. Consequently, perception is a psychological construction that is the conclusion of an incomplete and fallible set of sensory stimuli. Perception is functional because when individuals have better ability to construct or infer the true nature of a distal stimulus, they are able to make more accurate predictions about their environment, what increases the likelihood that they will survive. Figure 1 depicts the contemporary version of the lens model.

According to the lens model, each individual has the ability to recognize the heterogeneity of the environment and select the information on both the input (criterion) and output (judgment) sides. In other words, a man is able to choose what is important in a given situation and what should be ignored. This choice is possible thanks to the "cues" 


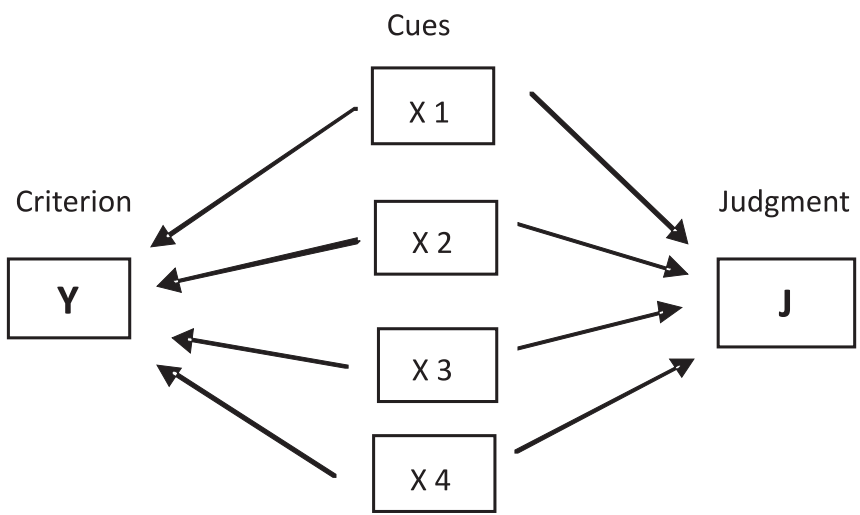

Figure 1. Brunswik's lens model

Source: M. Brannick, Lens model, faculty.cas.usf.edu/mbrannick/regression/Lens.doc (accessed:14th Oct 2018).

that are managed by the "central unit of the organism". The individual uses cues by choosing a criterion. The logic of the lens model is that the decisions of a given person reflect the degree to which his/her "trust" to cues is compatible with the environmental model. The accuracy of the assessment depends primarily on the extent to which, based on cues, the criterion used can be predicted, and to what extent the function describing the choice of a given person is compatible with his/ her environmental counterpart (so-called "ecology" using Brunswik's terminology). Brunswik believed that his model was a correct paramorphic ("as if") representation of how individuals subjectively used many information cues to make judgments (Wolf, 2000).

The lens model was and still is widely used in functional fixation research. One can even say that this is a superior and key concept in research in this field. Although behavioural accountants, while presenting a theoretical framework of their experiments, often do not even mention this model "by name", the construction of research methodology and the very essence of this phenomenon suggest that it was effectively in use. The reason behind that is its simplicity. Adopting the model into accounting area may look as follows. Accounting data are the task environment, the input side of the model (e.g. income statement and some accounting policy information on how the profit was calculated). The cues determine how the decision process goes, what is taken into account while making a choice (as far as data 
fixation is concerned, decision-maker may interpret profit amount in a way that he learned in the past regardless of the method used for its calculation). Output side is the final judgment, in that case being often fixated, meaning that the decision-maker fails to adjust his choice to changes in valuation method.

As far as research design is concerned, the most of experiments based on lens model had only one round. Subjects were given a data with a task to do and they were asked to make a choice. The existence of fixation was evidenced by comparing the results made by the experimental group, where decision process conditions changed during the round (i.e. FIFO - LIFO, full cost - variable cost etc.), with the results of control group where the conditions remained the same.

An example of an experiment where lens model had been applied was the one by Luft and Shields (2001) on:

(...) the role of accounting in the determination of intangibles expenditures on future profits. They predict and find that when intangibles expenditures are expensed (capitalized), individuals allocate more attention to learning current-period (future-period) effects of expenditures. Although experimental participants believe ex ante that intangibles will affect future profits regardless of whether they are expensed or capitalized, they learn the magnitude of future-period effects and use them better in predicting profits when intangibles are capitalized. Consistent with expectations, mean prediction error, achievement, consistency, consensus, and self-insight are all higher when intangibles are capitalized, holding constant the statistical relation between intangibles expenditures and profits (Chapman et al., 2007).

Another theory that functional fixation researchers invoke is prospect theory, which says that people behave differently depending on perceived gains or losses. The way people see a given situation (as a gain or as a loss), is determined by the initial recognition of the problem. That is called framing. Framing is a combination of how certain decision maker verbalises the problem and his norms, customs and personal features. Thus, framing occurs due to the fact that the way the problem is formulated affects the final decision. Hence, fixation can be treated as a result of choosing a given option of perceiving a decision-making task by a decision-maker (Belkaoui, 1989), i.e. as a framing variant. Having in mind above mentioned example of Luft and Schields (2001) experiment, fixation may also result from the participants initial 
notion (frame) of a cost or even loss when intangible expenditures are expensed. While capitalizing those expenditures postpones the feeling of a loss to the future.

Among the set of probabilistic judgment theories there are also decision heuristics. If it comes to functional fixation, anchoring and adjustment heuristic cannot be omitted. This mechanism consists in estimating the initial values and correcting them until the final value is obtained. The starting point however may be suggested externally while formulating the problem or may result from incomplete calculations. Depending on the starting point, the estimates may be different as they "skew" towards the initial value (Tversky \& Kahneman, 1974). The first step is cognitive anchoring of values. Next step are further adjustments and moving away from the adopted anchor (simplified adjustment of the value or price to the anchored level). Final choice is therefore dependent on a certain arbitrary value adopted while making estimates (Zielonka, 2006). It is worth noticing that the very concepts of fixation and anchoring seem quite similar in meaning. Arnold, following the idea (in Arnold \& Sutton, 1997), claims that functional fixation can be treated as a special variant of anchoring and insufficient adjustment to that "anchor". However, this issue requires further theoretical and empirical verification.

\section{LEARNING THEORY}

In research on functional fixation in accounting, the achievements of the theory of learning were abundantly used. In particular, many references were made to stimulus-response theory (including the conditioning hypothesis) and interference theory.

Stimulus-response theory describes the learning processes at the basic and higher level through connections that are formed as a result of the pairing of stimuli with the reactions experienced during our lives. When we grow, we encounter innumerable stimulus-response connections that result in learning outcomes. Different stimuli are generalized what means that we react in a similar way to similar types of stimuli that appear in our environment. Learning outcomes are encoded in our brains and form the basis for understanding and adapting to the world around us. The key element of stimulus-response theory is the conditioning hypothesis. In studies on functional fixation, 
instrumental conditioning is relevant (not classical conditioning discovered by Pavlov), where the subject learns the relationship between the reaction and its consequences (Strelau, 2006). To shape behaviour consequences are indispensable. Consequences mean reinforcements and punishments occurring in coincidence with a given behaviour. The law of effect formulated by Thordike (Strelau, 2006) states that the behaviour that causes satisfaction in a given situation is associated with this situation and if the situation repeats in the future, then the likelihood that such a behaviour will repeat also increases. If the behaviour causes discomfort then the probability of its repetition in similar conditions in the future decreases. There are also preceding stimuli, which are a signal for the body to perform a previously learned reaction.

Here is an example of how conditioning works in accounting. Sterling (1970) concludes that the "production" of reports is accompanied by an "impressive ceremony" involving both managers and accountants. Therefore, the recipients of these reports seem to have to react to them since they are a result of a complicated ritual in which many people take part. Thus, accountants react to financial data because they are taught (conditioned) to respond to them, and not because given data actually have significant informational content. And even if they have it, the question remains whether or not the accountants react in the right way (Belkaoui, 1989). They may simply react in a previously learned way, no matter what methods were used to get the results. If they took into account these methods it would require changing their behaviour, what means incurring additional psychological "costs". It is worth remembering that accountants in the course of their professional education become familiar with the accounting principles, procedures and methods as well as financial reports that arise as a result of the application of these principles or procedures. In addition, they learn ratio analysis or cash flow methodology where accounting data are used to assess the company's performance and prospects. Thus, in the learning process, they are in a way "indoctrinated" in how to assess the relevance and usefulness of information from the accounting system. In addition, this "indoctrination" is constantly reinforced by every report they receive in their daily work.

Interference theory states that the learning process consists of socalled transfer of skills or proaction. Previously acquired prowess affects the learning of a new activity. Influence can be both positive (positive 
transfer), which can accelerate the learning process, as well as negative (negative transfer), i.e. impeding the change of reflexes or habits needed to acquire new skills (Haka et al., 1986). A reverse phenomenon is also known. Its name is retroaction, where new experiences affect the remembrance of previous ones. It is about changing the effects of prior learning as a result of acquiring new material between the end of learning and measuring the result. If the absorption of new information reduces the effectiveness of recalling previously learned content, we are talking about retroactive interference. If the effect of learning is to increase the effectiveness of reminding, retroactive facilitation takes place. Thus, functional fixation is a "classic example of negative transfer" (to be more precise - of negative retroaction) (Haka et al., 1986).

Figure 2 illustrates the typical course of the fixation experiment based on this theory.

$\begin{array}{lll}\text { Learn Task } 1 & \text { Learn Task } 2 & \text { Test Task } 1\end{array}$

Learn Task 1

Test Task 1

Figure 2. Retroactive interference

Source: Based on: Haka et al., 1986, p. 458.

Such an experiment had often three (or sometimes more) rounds (in contrast to research based on lens model where in most cases only one round was applied). First round was usually dedicated to learning some experimental task. Second round was to test what was learned before (for control group) or to learn another task (for experimental group). Then in third round experimental group were subject to final testing that showed the concluding learning results.

An example of research designed basing on interference theory may be an experiment conducted by Haka et al. (1986). The idea was that people learn to use e.g. cost categories or profit categories in tax-related or business-related contexts. "Solidification" of these methods can be so strong that the use of these categories for rational determination of product prices based not only on the production costs (conservative pricing), but also taking into account market data (modern approach) can be a problem. 
Undeniably also memory plays an important role in the learning process. Memory is defined as a "process responsible for recording, storing and reproducing experience" (Strelau, 2006). Primacy and recency effects are closely related to human memory. Psychologists say that under stress the body triggers a behaviour, which for a given situation (for a given type of problem) was learned first (primacy). From the functional fixation research point of view it would be an interesting idea to verify whether the sequence of issues that people assimilate within a given topic affects the fixation. In other words, if the two sides of a problem were presented successively which of them, the first (primacy) or the last (recency), would have a greater impact on the final decision. Research in the area of accounting has not yet provided a definite answer to the question which of the two mechanisms acts stronger. In certain situations the primacy effect turned out to be stronger, in others - the recency (Belkaoui, 1989).

\section{MOTIVATION THEORY}

Theories, concepts or models characterized thus far served primarily to explain why fixation occurs in accounting-related situations. The last group of theories relevant to functional fixation research mentioned above, that is motivation theories, seem to have a slightly different function. Dearman and Shields (2005) in their experiment, as one of the few, dealt with factors (that is individual characteristics) that can eliminate fixation in accounting. Their experimental design included such factor as intrinsic motivation. The way the researchers understood it suggested that self-determination theory was in use therein. Self-determination theory perceives man as an active organism with a potential for action. The sources of human potential are located inside each individual (e.g. drives, emotions), as well as in the environment in which it operates. Intrinsic motivation is associated with a sense of competence, control or freedom that results from the performance of an interesting task and manifests itself in enjoying the sole activity. In accounting, intrinsic motivation is treated as a factor encouraging creative and flexible decision-making (Ryan \& Deci, 2000a, 2000b). Lack of intrinsic motivation causes that individuals, most likely subconsciously, impose themselves some time limits on the task and apply the acceptability criterion (instead of looking for the best solution, 
they sub optimize instead of optimizing) to find a solution quickly and without big effort. Such practice makes their goals become inconsistent with the goals originally assumed in the decision problem (Dearman \& Shields, 2005). The lack of strong intrinsic motivation makes it difficult to prevent fixation, because individuals avoid cognitive effort needed to creatively and properly engage in the decision-making task. They rather stick to a familiar, comfortable and not very demanding way of thinking instead.

Dearman and Shields thus seem to have initiated research trend devoted to individual attributes of a decision maker and their role in reducing fixation. Such attributes do not mean only motivation but also temperamental and personality traits or stress reactions that can be investigated using personality theory or stress and coping theory. However those theories have not been yet applied in data fixation research.

\section{CONCLUSION}

While constructing the theoretical framework for functional fixation research in accounting, many psychological concepts were used. It should be noted that most of them aimed to assess whether and why fixation occurred, that is to explain the genesis of this phenomenon. To this end, the behavioural decision theory and learning theory was exploited. Behavioural decision theory concentrates on the decision process, that is mainly on the way how its inputs turn into outputs and what mechanisms influence it. Learning theory focuses rather on describing the way people absorb, process or retain knowledge as well as analysing cognitive, emotional, environmental and experiential influences on acquiring knowledge and skills. The choice of theory underlying a given functional fixation research undoubtedly determines its design and the way of interpreting conclusions. Research where Brunswik lens model approach was adopted focused more on input and output side of experiment while those based on interference theory concentrated rather on the learning process itself.

Data fixation, as many others human flaws, is quite complex. That is why it seems difficult to investigate it on the basis of one theory or model. Certain concepts interpenetrate and complement one another. Data fixation research, even if declaratively based on the 
lens model (as stated by their authors), sometimes included feedback that was given to subjects after completing a task. Feedback means an information about the validity of a previously made decision. Getting feedback enabled experimental subjects to learn and to correct their future judgment. That is how behavioural decision theory and learning theory "cooperated". And if learning is concerned, the issue of human memory functioning cannot be omitted. Even the order in which the tasks to be learned by experimental subjects had been presented seemed to influence the final research outcomes that is fixation occurrence or avoidance.

Functional fixation research carried out so far were less focused on those theories that would help in finding ways to prevent fixation, such as motivation theory. There are not so many studies including such a reflection. However, existent ones indicate that "wanting" has a great potential for preventing fixation. It needs to be mentioned that motivation theory has not been treated so far as a main theory for the accounting fixation research. Its function was rather supplementary or backup. Thus, research based on motivation theory can significantly contribute to discoveries that will reduce or even prevent the appearance of fixation in accounting.

It seems, however, that neither explanatory nor preventative potential in the aforementioned groups of theories, as well as in many others, has yet been exhausted. For example, when it comes to learning theories, information processing theory could be fruitfully exploited here. Also personality theory could play a role in verifying whether certain types of personality are more prone to fixity than others. Interesting discoveries could be made using the achievements of neuroscience, which in recent years attracts more and more interest among researchers, and thus go beyond the rather harsh framework of psychology towards biology or medicine. It may be also possible to explain fixation basing on cybernetics, which, similarly to behavioural accounting, is interdisciplinary in nature, but is already at a higher level of its development and is a separate scientific discipline with its own theoretical apparatus. 


\section{REFERENCES}

Arnold, V. \& Sutton, S. (1997). Behavioral Accounting Research: Foundations and Frontiers. Sarasota FL: American Accounting Association.

Artienwicz, N. (2011). Możliwości badania zachowania księgowych w świetle paradygmatów rachunkowości. Prace $i$ Materiały Wydziału Zarzqdzania Uniwersytetu Gdańskiego, 1/2, 355-363.

Belkaoui, A. (1989). Behavioral Accounting: The Research and Practical Issues. New York: Quorum Books.

Bloom, R., Elgers, P. \& Murray, D. (1984). Functional fixation in product pricing: A comparison of individuals and groups. Accounting, Organizations and Society, 9(1), 1-11.

Briers, M., Luckett, P. \& Chow, Ch. (1997). Data fixation and the use of traditional versus activity-based costing systems. ABACUS, 33(1), 1-20.

Chapman, C.S., Hopwood, A.G. \& Shields, M.D. (eds.) (2007). Handbook of Management Accounting Research. Oxford: Elsevier Ltd.

Dearman, D. \& Schields, M. (2005). Avoiding accounting fixation: Determinants of cognitive adaptation to differences in accounting method. Contemporary Accounting Research, 22(2), 351-384.

Duncker, K. (1946). On Problem Solving. Vol. 58. Washington DC: American Psychological Association INC.

Gmińska, R. (2014). Aspekty behawioralne w rachunkowości zarządczej. Prace Naukowe Uniwersytetu Ekonomicznego we Wrocławiu, 344, 185-193.

Haka, S., Friedman, L. \& Jones, V. (1986). Functional fixation and interference theory: A theoretical and empirical investigation. The Accounting Review, 61(3), 455-474.

Hammond, K.R. \& Stewart, T.R. (2001). The Essential Brunswik. Beginnings, Explications, Applications. London: Oxford University Press.

Ijiri, Y., Jaedicke, R. \& Knight, K. (1966). The effects of accounting alternatives on management decisions. In: Y. Ijiri \& O. Nielson (eds.). Research in Accounting Measurement. Sarasota FL: American Accounting Association, 186-199.

Korzeniowska, D. (2018a). The subject of behavioural accounting research. Zeszyty Teoretyczne Rachunkowości, 98(154), 147-165.

Korzeniowska, D. (2018b). Zjawisko fiksacji funkcjonalnej w rachunkowości. Przedsiębiorczość i Zarzadzanie, 19(10) [in press].

Luft, J. \& Schields, M. (2001). Why does fixation persist? Experimental evidence on the judgment performance effects of expensing intangibles. The Accounting Review, 76(4), 561-587. 
Mazurowska, M. (2014). Paradygmat homo oeconomicus a rachunkowość behawioralna. Studia Oeconomica Posnaniensia, 2(4), 88-101.

Ryan, R.M. \& Deci, E.L. (2000a). Intrinsic and extrinsic motivations: Classic definitions and new directions. Contemporary Educational Psychology, 25, 54-67.

Ryan, R.M. \& Deci, E.L. (2000b). Self-determination theory and the facilitation of intrinsic motivation, social development, and well-being. American Psychologist, 55(1), 68.

Simon, H.A. (1955). A behavioral model of rational choice. The Quarterly Journal of Economics, 69(1), 99-118.

Sterling, R. (1970). On theory construction and verification. The Accounting Review, $433,444-457$.

Strelau, J. (ed.) (2006). Psychologia, t. 2. Gdańsk: Gdańskie Wydawnictwo Psychologiczne.

Tversky, A. \& Kahneman, D. (1974). Judgement under uncertainty. Heuristics and biases. Science, 185, 1124-1131 [reprint in: Kahneman, D. (2012), Pułapki myślenia. O myśleniu szybkim i wolnym. Tłum. P. Szymczak. Poznań: Media Rodzina].

Wolf, B. (2000). The Structure of the Human World: Brunswik's Organism-Environment-Model. Notes and Essays, http://www.brunswik.org. (accessed: 4th Oct 2018).

Zielonka, P. (2006). Behawioralne aspekty inwestowania na rynku papierów wartościowych. Warszawa: CeDeWu. 